\title{
ANALYSIS OF CARBON EMISSION REDUCTION AND PRICING FOR SUSTAINABLE CLOSED-LOOP SUPPLY CHAIN CONSIDERING THE QUALITY OF RECYCLED PRODUCTS
}

\author{
WAN, P. ${ }^{*}-$ MA, L. X. - LIU, J. N. \\ School of Management Engineering, Qingdao University of Technology, Qingdao 266520, \\ Shandong Province, China \\ (e-mail: 2044772948@qq.com,wpie99@126.com) \\ *Corresponding author \\ e-mail:pengwan@qut.edu.cn; phone: +86-532-8687-5070 \\ (Received $5^{\text {th }}$ Apr 2019; accepted $13^{\text {th }}$ Jun 2019)
}

\begin{abstract}
Sustainable closed-loop supply chains have attracted attention due to environmental protection problems and resource shortages. The quality of recycled products is an important factor in reverse logistics. Based on Stackelberg game theory, we propose two sustainable closed-loop supply chain models: a centralized decision model and a decentralized decision model, and assume that the manufacturer considers the recycling quality level of used products. We compare the differences in the optimal decisions from different decision-makers and analyze the influence of relevant parameters on these decisions in a sustainable closed loop supply chain. From the comparative analysis and numerical analysis, it was observed that the model yields the best decision result and carbon emission reduction level under the centralized decision condition. The recycling quality level is found to be higher in the centralized decision model than in the decentralized decision model, and the sales price is found to be lower in the centralized decision model than in the decentralized decision model. Moreover, the impacts on the carbon emission reduction level, the recycling quality level, and corporate profit are found to be related to the carbon emission preference coefficient of consumers, the recycling effort cost coefficient, and the carbon emission investment cost coefficient.
\end{abstract}

Keywords: environmental constraints, game theory, carbon emission, recycling effort, remanufacturing, sustainable supply chain

\section{Introduction}

With the progress in production technology and the diversification of consumer demand, product life cycles are becoming shorter, product upgrades are becoming faster, and the number of eliminated and used products has increased dramatically. At the same time, the Earth's resources are dwindling, and the call for sustainable development is growing. This has made the world's major countries give more consideration to problems of energy conservation and environmental protection. Resource and environmental pressure, as well as laws, regulations, and consumer awareness of environmental protection, are increasing. The recycling and remanufacturing of used products have become a hot issue. Since closed-loop supply chains (CLSCs) have achieved significant results in sustainable development management practices, CLSCs have also become an important topic in the academic area (Savaskan et al., 2004; Savaskan and Van Wassenhove, 2006).

For enterprises, on the one hand, recycling of used products is the responsibility of manufacturers. Recycling of used products can reduce carbon emissions, save resources, reduce negative impacts on the environment, create a good corporate image, and improve the competitiveness of enterprises. On the other hand, enterprises can realize value-added materials, save on costs, and improve their profits through recycling and reuse of used 
products (Govindan et al., 2016). From the perspective of recycling, because the time, frequency, and method of a consumer's use of a product may differ, the degree of loss of the product can also be various. According to the different degrees of product loss, we divide recycled products into different quality levels. The quality of recycled products is one of the main factors affecting the operation of a closed-loop supply chain. Low-quality recycled products have a negative effect on enterprises that remanufacture used products (Rahman and Subramanian, 2012). Therefore, the quality level of recycled products is an issue for remanufacturers to consider and is also one of the focuses of our research.

After the Copenhagen climate conference, a low-carbon economy, which pursues a reduction in energy consumption, pollution, and greenhouse gas (GHG) emissions, was listed as one of the most important strategies for global climate change mitigation. Olugu and Wong state that one of the objectives of closed-loop supply chain management is to reduce carbon emissions (Olugu and Wong, 2012). The recycling of used products through a closed-loop supply chain to reduce carbon emissions is a part of reverse logistics. For forward logistics, the manufacturing of new products also needs to consider the problem of reducing carbon emissions. The study of carbon emissions from a sustainable closed-loop supply chain perspective focuses not only on emissions at specific stages of production (such as used product recycling), but also on the social and environmental impacts of a product over its entire life cycle (Metta and Badurdeen, 2013). A carbon emission reduction not only affects the profit of a closed-loop supply chain, but also affects the pricing and recycling decisions of supply chain members. Enterprises need to operate under certain environmental incentives and seek the optimal pricing and emission reduction strategies under the sustainable development goals (Ding et al., 2015).

Carbon emission reduction involves the joint efforts of a sustainable closed-loop supply chain's members. In a closed-loop supply chain where the manufacturer is responsible for recycling, the manufacturer may increase the cost of the product through a low-carbon investment. However, due to consumers' awareness of the environmental features of the product, the cost increase will increase consumers' intention to purchase the product, increase the sales price, and promote increases in the scale of sales. It benefits retailers from a carbon emissions reduction perspective as well. Recycling of used products and investment in new products that reduce carbon emissions have environmental benefits. We consider the following questions: How do manufacturers weigh the impact of recycling quality on carbon reduction levels? How does the retailer decide the selling price? How do the recycling quality level, carbon emission reduction level, recovery rate, consumer preferences, emission reduction and recycling investment coefficient, and other relevant factors affect each other?

This study considers these carbon emissions reduction and pricing decision problems considering recycling quality in the context of a sustainable closed-loop supply chain. Consumer preferences, such as recycling quality, carbon emissions reduction level, and sales price, are used as decision variables to establish a sustainable closed-loop supply chain decision-making model and find out how manufacturers can adjust their own recycling policies and emission reduction investment strategies to maximize revenue. Then, through a numerical simulation, we analyze the impact of recovery rate on recovery quality, emissions reduction level, pricing, and closed-loop supply chain profit. Our goal is not only to enhance the sustainable closed-loop supply chain decision-making optimization theory, but also provide a theoretical basis for enterprises to make emissions 
reduction decisions, recycling decisions, and pricing decisions as well as promote the realization of emissions reduction targets.

Our study contributes to the literature in three main regards. First, our study investigates the quality of recycled products in a sustainable closed-loop supply chain for carbon emissions reduction, which complements the existing literature in which sustainable closed-loop supply chains for carbon emissions reduction are not considered (Shu et al., 2018; Xu and Wang, 2018). Second, our work compares a centralized decision CLSC model with a decentralized decision CLSC model for manufacturers who directly recycle used products. We obtain a few appealing management insights. Third, our model analyzes the impact of various factors on decision-making in, and the profits of, CLSCs.

\section{Review of literature}

We review the following three streams of literature related to this work: closed-loop supply chains that consider the quality level of recycled products; closed-loop supply chain pricing, and closed-loop supply chains for carbon emissions reduction.

\section{Closed-loop supply chains that consider the quality level of recycled products}

Many researchers have discussed the quality level of recycled products in closed-loop supply chains. Guide et al. (2003) studied used product recovery pricing and remanufactured product sales pricing issues for a variety of quality grades. They assumed that the quality grades of used products are sensitive to the recovery cost. Savaskan et al. (2004) assumed that recovery quality is a random variable subject to a uniform distribution, and discussed the selection of recycling strategies in different environments. Dobos and Richter (2006) introduced recycled product quality into a productionrecycling system, and assumed that if a recycled product's quality level is too low, it cannot be used in the remanufacturing process. Galbreth and Blackburn (2006) studied the optimal recovery and remanufacturing classification strategy under the condition of uncertain quality of recovered products. In their classification strategy, recycled products are generally treated in one of two ways after testing: if their unit remanufacturing cost is lower than the optimal cost level, they are used in remanufacturing production; otherwise, they are directly abandoned. Mukhopadhyay and Ma (2009) studied optimal procurement and production decisions in remanufacturing systems with uncertain quality of and demand for recycled products. Özkır and Başligıl (2012) described the specific features of green supply chain design with consideration of end-of life products and pointed out that considering the quantity and quality of recycled products can improve the system's profitability. Chen et al. (2015) designed a two-stage dynamic closed-loop supply chain that considers uncertainty in the quantity and quality of recycled products as well as differences in the willingness-to-pay of consumers. Jerbia et al. (2018) studied a closedloop supply chain network design problem. A scenario-based approach was used to model the uncertainties in return rates, revenues, costs, and the quality of returns. Tan and Guo (2019) studied the impact of regulatory environments on the operation of a logistics system that considers the uncertainty in the quality of recycled products and the controllability of the remanufacturing technology level. The models discussed above consider the quality of recycled products in network or channel selection; they do not consider the impact of the quality of recycled products on pricing decisions and carbon emissions reductions. Next, we review the literature on closed-loop supply chain pricing. 


\section{Closed-loop supply chain pricing}

As an important function of a closed-loop supply chain, pricing has a direct impact on product demand and competitive advantage. Ferrer and Swanminathan (2006) studied closed-loop supply chain pricing decisions in a monopoly environment and explored the effect of various parameters on the Nash equilibrium. Swanminathan and Ferrer (2010) analyzed two-period, multiperiod, and infinite planning horizons in a monopoly environment, and characterized the optimal remanufacturing and pricing strategy. Bulmus et al. (2014) considered differences in recycling quality level, divided used products into several different types, and determined the recycling price of different types of used products and the selling price of new products. Gan et al. (2017) developed a pricing decision model for short life-cycle products in a closed-loop supply chain and found that scaling factors influence both the pricing decisions and the profits of the supply chain's members. Gao et al. (2016) provided centralized and decentralized game-theoretic models of a CLSC and investigated optimal decisions on collection effort and pricing under different channel power structures. Ke et al. (2018) studied a pricing and remanufacturing decision problem in a fuzzy closed-loop supply chain with one manufacturer, two competitive retailers, and one third-party collector. Taleizadeh et al. (2019) studied pricing decisions and discounts on returned products in a multiperiod, multi-echelon, and sustainable closed-loop supply chain. Some researchers have also considered the quality of recycled products when studying pricing in closed-loop supply chains. Zou and Ye (2015) studied pricing strategies for and the coordination mechanism of a supply chain when the remanufacturing cost is random and caused by a recycled product's quality. Taleizadeh et al. (2017) proposed a joint optimization model of pricing strategies, quality levels, effort decisions, and return policies by considering the reference price effect in a three-level supply chain under different channel power structures. The abovementioned studies have taken into account the impact of recycled products' quality level in pricing decisions; however, they did not consider environmental constraints.

\section{Closed-loop supply chains for carbon emissions reduction}

The research related to our work concerns carbon emission issues in a closed-loop supply chain. Feng et al. (2017) estimated the economic benefits associated with policy regulations for manufacturers in a low-carbon technology market. They indicated that when the punishment levied on a manufacturer is sizable, the manufacturer will be prone to developing innovative technology. The objective when reducing carbon emissions is not only to respect environmental regulations; it is also to increase profit. Unlike forward supply chains, Brandenburg et al. (2014) believed that environmental and social issues have received very little attention in CLSC models. Carbon emissions have only recently been incorporated into reverse supply chain and CLSC modeling. Govindan et al. (2015) emphasized the need for the investigation of environmental issues and new directions in reverse logistics and closed-loop supply chain research. Fareeduddin et al. (2015) proposed models for three common regulatory policies to optimize not only costs but also emissions in supply chain operations. Tao et al. (2015) studied the CLSC network equilibrium problem in a multiperiod planning horizon, where manufacturers make homogeneous products and have two types of mandatory carbon emission. He et al. (2016) evaluated the impact of consumer free riding on carbon emissions across a product's life cycle in a dualchannel closed-loop supply chain. Bazan et al. (2017) considered the carbon emissions from and the energy cost of a vendor-managed inventory with a consignment stock policy. Xu et 
al. (2017) analyzed the effect of considering carbon emissions on the design of both hybrid and dedicated CLSCs. Fang et al. (2017) studied carbon emission reductions under a carbon cap-and-trade scheme and reverse logistics in a production routing problem. Shu et al. (2018) studied optimal decisions for closed-loop supply chains in the framework of social responsibility and explored the impacts of carbon emissions constraints and corporate social responsibility on recycling and remanufacturing decisions. Turki and Rezg (2018) provided an optimal design for a manufacturing/remanufacturing system that differentiates between new and remanufactured products and sorts the used products into three quality levels. Yang et al. (2017) considered two competitive supply chains under the cap-and-trade scheme and studied pricing and carbon emissions reduction decisions. Li et al. (2017) studied the influence of vertical and horizontal cooperation models on the optimal decisions for and performance of a low-carbon closed-loop supply chain with respect to pricing, carbon emissions reduction, used product collection, and profit.

It can be seen from the above literature that the quality level of recycled products has a great impact on the performance of a closed-loop supply chain. Although the quality of recycled products can be graded and the recycling price can vary, this increases the difficulties that recyclers face. It is easier to recycle used products at a set quality level and a fixed price. Therefore, unlike previous research, we consider that the market demand depends on the sale price and the carbon emissions reduction level set by the manufacturer. We carry out the study in accordance with a fixed quality level of recycled products, research pricing and carbon emissions reduction decisions in a closed-loop supply chain, and analyze the sensitivity of the main parameters using a numerical example. We hope to provide a theoretical basis on which related enterprises can make recycling and carbon emissions reduction decisions.

\section{Materials and methods}

\section{Assumptions and model description}

This section may be divided by subheadings. It should provide a concise and precise description of the experimental results, their interpretation as well as the experimental conclusions that can be drawn.

From an environmental protection perspective, reductions in carbon emissions are conventionally considered to be a burden for manufacturers. This paper considers a closedloop supply chain composed of a manufacturer and a retailer. The manufacturer uses new materials to make new products and also remanufactures used products. The manufacturer is responsible for recycling used products that are recovered directly from consumers. The retailer is responsible for the sale of the products. In a forward supply chain, the unit cost of manufacturing a new product is $c_{m}, w$ is the wholesale price of the product as determined by the manufacturer, the selling price of the retailer is $p$, and the market demand is a linear function of price and the carbon emissions reduction. In a reverse supply chain, the manufacturer divides the used products into different quality levels according to the degree of damage, which is represented by $q(0<q<1)$. The unit recovery cost of an old product that the manufacturer recovers from a consumer is represented by $A(q)$, which is a function of the quality of the recovered product. The higher the quality of the recovered product, the higher the recovery cost. $A(q)=a q, a$ is the maximum unit recovery price of a used product that the manufacturer pays to the customer. The used product recycling rate is 
$\varepsilon$, which is considered to be an exogenous variable, such as government regulations. We only consider carbon emissions in the production process. The manufacturer can improve their carbon emissions reduction technology to reduce the carbon emissions per unit product.

To simplify the research problem and facilitate the analysis, we make the following assumptions:

(1) The manufacturer is the core enterprise of the supply chain and is the leader in the game process. We do not consider an out-of-stock scenario; namely, the production quantity is the market demand. Remanufactured products and new products are sold at the same price, with no difference in quality and performance. Considering the cost advantage, manufacturers give priority to using remanufactured products to meet the market demand. Following Atasu et al. (2013), it is assumed that all recycled products are used in the remanufacturing process. The unit cost of remanufacturing is denoted by $c_{r}(q)$, and is a function of the quality of the recycled product $\left(c_{r}(q)<c_{m}\right)$. Let $c_{r}(q)=c_{m}-c_{s} q$. Then, is the unit cost savings through remanufacturing. To ensure that the remanufacturing process is feasible, let $c_{s} q<A(q)$, i.e., $a<c_{s}$.

(2) The manufacturer needs to invest in low-carbon production technologies to reduce its carbon emissions. Only investment in carbon emissions reduction for new products is considered here, and the required capital is a one-time investment, which is independently undertaken by the manufacturer. The reduction rate per unit product is $\lambda(0<\lambda<1)$. Following Ghosh and Shah (2012), the emissions reduction cost that the manufacturer pays is $\beta \lambda^{2} / 2$, where $\beta$ denotes the carbon emissions reduction investment cost coefficient, which is a large number.

(3) To recycle higher-quality used products, manufacturers must pay higher effort costs. Similarly to the cost of the carbon emissions reduction investment, let $I(q)=K q^{2}$. $K(K>0)$ denotes the recycling effort cost coefficient, which is a large number.

(4) The demand is a linear function of the manufacturer's carbon emissions reduction level and the retailer's sales price. Following Liu et al. (2012) and Zhang et al. (2014), the demand function is $D=V-b p+\gamma \lambda$, where $V$ denotes the potential demand scale of the market, $b$ is the sensitivity coefficient of the retail price, and $\gamma$ is the coefficient of consumers' carbon emissions reduction preferences.

In addition, we assume that both manufacturers and retailers are risk-neutral, and we ignore the carbon emissions of retailers in this study. The subscript $c$ denotes a centralized decision.

\section{Modeling and decision analysis}

Based on the above assumptions, let $c(q)=c_{m}(1-\varepsilon)+c_{r}(q) \varepsilon$. The simplification $c(q)=c_{m}-c_{s} q \varepsilon$, the manufacturer's revenue $\pi_{m}$, and the retailer's revenue $\pi_{r}$ are exhibited as follows:

$$
\begin{aligned}
\max \pi_{m}= & \left(p-c_{m}+\varepsilon c_{s} q\right)(V-b p+\gamma \lambda)-a \varepsilon q(V-b p+\gamma \lambda)-\left(\beta \lambda^{2} / 2\right)-K q^{2} \\
& =\left(w-c_{m}+\left(c_{s} q-a\right) \varepsilon q\right)(V-b p+\gamma \lambda)-\left(\beta \lambda^{2} / 2\right)-K q^{2}
\end{aligned}
$$




$$
\max \pi_{r}=(p-w)(V-b p+\gamma \lambda)
$$

The total supply chain profit is expressed as follows:

$$
\pi=\pi_{m}+\pi_{r}
$$

\section{The decentralized decision system for the manufacturer as leader}

We assume that, in this situation, the manufacturer is a leader and the retailer is a follower in a Stackelberg game. The partners' action order is given as follows: (1) the manufacturer determines the carbon emissions reduction rate $\lambda$, the wholesale price $w$, and the quality level of recycled products $q$; then (2) based on the manufacturer's declared decisions, the retailer determines the sales price $p$.

We first derive the optimal reaction of the retailer.

Proposition 1. In a decentralized decision situation, after determining the wholesale price $w$, the carbon emissions reduction rate $\lambda$, and the recycled product quality level $q$, the optimal sales price for the retailer is $(E q .4)$ :

$$
p^{*}=\frac{V+\gamma \lambda+b w}{2 b}
$$

Proof of Proposition 1. For Equation 2, the first-order partial derivation of $\pi_{r}$ to $p$ can be expressed as

$$
\frac{\partial \pi_{r}}{\partial p}=V-2 b p+\gamma \lambda+b w
$$

We use the second-order partial derivatives to confirm the optimality:

$$
\frac{\partial^{2} \pi_{r}}{\partial p^{2}}=-2 b
$$

Equation 6 indicates that $\pi_{r}$ is concave. Therefore, the succeeding first-order conditions can be obtained by setting Equation 5 to zero

$$
V-2 b p+\gamma \lambda+b w=0
$$

We can obtain Equation 4 by solving Equation 7; thus, Proposition 1 is proven.

From Equation 4 it can be seen that the optimal retail price is a linear function of the carbon emissions reduction level and the wholesale price and increases monotonously. Therefore, manufacturers can influence retailers' optimal pricing decisions through carbon emissions reduction and wholesale price decisions.

Now that we know the retailer's decisions, we can derive the manufacturer's optimal decision. We substitute Equation 4 into Equation 1 to obtain the manufacturer's optimal profit function: 


$$
\max \pi_{m}=\left(w-c_{m}+\varepsilon c_{s} q-a \varepsilon q\right)\left(\frac{V+\gamma \lambda-b w}{2}\right)-\left(\frac{\beta \lambda^{2}}{2}\right)-K q^{2}
$$

Proposition 2. In a decentralized decision situation, the manufacturer's optimal decision is obtained as follows:

$$
\begin{gathered}
w^{*}=\frac{\left(c_{s}-a\right)^{2} \beta V b \varepsilon^{2}+2 K c_{m} \gamma^{2}-4 K \beta b c_{m}-4 K \beta V}{\left(c_{s}-a\right)^{2} \beta b^{2} \varepsilon^{2}+2 K \gamma^{2}-8 K \beta b} \\
\lambda^{*}=\frac{\left(b c_{m}-V\right) 2 K \gamma}{\left(c_{s}-a\right)^{2} \beta b^{2} \varepsilon^{2}+2 K \gamma^{2}-8 K \beta b} \\
q^{*}=\frac{\left(c_{s}-a\right)\left(b c_{m}-V\right) \beta b \varepsilon}{\left(c_{s}-a\right)^{2} \beta b^{2} \varepsilon^{2}+2 K \gamma^{2}-8 K \beta b}
\end{gathered}
$$

Proof of Proposition 2. To find the optimal wholesale price $w$, the carbon emission reduction level $\lambda$, and the recovery quality level $q$, the first-order derivative of Equation 8 to $w, \lambda$, and $q$ can be expressed as:

$$
\begin{gathered}
\frac{\partial \pi_{m}}{\partial w}=\frac{V+\gamma \lambda-2 b w+b c_{m}-b \varepsilon c_{s} q+b a \varepsilon q}{2} \\
\frac{\partial \pi_{m}}{\partial \lambda}=\left(w-c_{m}+\varepsilon c_{s} q-a \varepsilon q\right)\left(\frac{\gamma}{2}\right)-\beta \lambda \\
\frac{\partial \pi_{m}}{\partial q}=\left(\varepsilon c_{s}-a \varepsilon\right)\left(\frac{V+\gamma \lambda-b w}{2}\right)-2 K q
\end{gathered}
$$

The Hessian matrix of the objection functions of the manufacturer's profit is expressed as follows:

$$
H\left(\pi_{m}\right)=\left[\begin{array}{ccc}
-b & \frac{\gamma}{2} & \left(\frac{-b}{2}\right)\left(\varepsilon c_{s}-a \varepsilon\right) \\
\frac{\gamma}{2} & -\beta & \left(\frac{\gamma}{2}\right)\left(\varepsilon c_{s}-a \varepsilon\right) \\
\left(\frac{-b}{2}\right)\left(\varepsilon c_{s}-a \varepsilon\right) & \left(\frac{\gamma}{2}\right)\left(\varepsilon c_{s}-a \varepsilon\right) & -2 K
\end{array}\right]
$$

According to this paper's assumptions, we derive $\left|H\left(\pi_{m}\right)_{1}\right|=-b<0$ and $\left|H\left(\pi_{m}\right)_{2}\right|=\frac{1}{2}\left(2 b \beta-\gamma^{2}\right)>0$, when $\left|H\left(\pi_{m}\right)_{3}\right|=-2 b \beta K+\left(\frac{\gamma}{2}\right)^{2} 2 K+\left(\varepsilon c_{s}-a \varepsilon\right)^{2}\left(\frac{b}{2}\right)^{2} \beta<0$, 
which indicates that the Hessian matrix is negative-definite. Hence, $\pi_{m}$ is jointly concave in $(w, \lambda, q)$. Consequently, we can obtain the unique optimal solutions $\left(w^{*}, \lambda^{*}, q^{*}\right)$ with the conditions assumed by the following first-order differential equations:

$$
\left\{\begin{array}{l}
\frac{\partial \pi_{m}}{\partial w}=\frac{V+\gamma \lambda-2 b w+b c_{m}-b \varepsilon c_{s} q+b a \varepsilon q}{2}=0 \\
\frac{\partial \pi_{m}}{\partial \lambda}=\left(w-c_{m}+\varepsilon c_{s} q-a \varepsilon q\right)\left(\frac{\gamma}{2}\right)-\beta \lambda=0 \\
\frac{\partial \pi_{m}}{\partial q}=\left(\varepsilon c_{s}-a \varepsilon\right)\left(\frac{V+\gamma \lambda-b w}{2}\right)-2 K q=0
\end{array}\right.
$$

Solving Equation 16, Equations 9, 10, 11 can be obtained; thus, Proposition 2 is proven.

Proposition 3. In the decentralized decision case, the retailer's optimal sales price is

$$
p^{*}=\frac{\left(c_{s}-a\right)^{2} V \beta b \varepsilon^{2}-6 K V \beta+2 K c_{m}\left(\gamma^{2}-\beta b\right)}{\left(c_{s}-a\right)^{2} \beta b^{2} \varepsilon^{2}+2 K \gamma^{2}-8 K \beta b}
$$

Proof of Proposition 3. By Propositions 1 and 2, we can obtain that Proposition 3 holds.

Using Equations 9, 10, 11, 17, 1, and 2, $\pi_{r}^{*}, \pi_{m}^{*}$, and $\pi$ can be expressed as follows:

$$
\begin{gathered}
\pi_{r}^{*}=\frac{4 b\left(K \beta b c_{m}-K V \beta\right)^{2}}{\left(\left(c_{s}-a\right)^{2} \beta b^{2} \varepsilon^{2}+2 K \gamma^{2}-8 K \beta b\right)^{2}} \\
\pi_{m}^{*}=\frac{-\left(b c_{m}-V\right)^{2} \beta K}{\left(\left(c_{s}-a\right)^{2} \beta b^{2} \varepsilon^{2}+2 K \gamma^{2}-8 K \beta b\right)} \\
\pi=2 K \beta\left(6 K b \beta-K \gamma^{2}-\left(c_{s}-a\right)^{2} \beta b^{2} \varepsilon^{2}\right)\left(\frac{\left(b c_{m}-V\right)}{\left(c_{s}-a\right)^{2} \beta b^{2} \varepsilon^{2}+2 K \gamma^{2}-8 K \beta b}\right)^{2}
\end{gathered}
$$

\section{The centralized decision system}

In the case of centralized decision, manufacturers and retailers jointly determine the sales price, carbon emissions reduction level, and recycled product quality level to maximize the profit of the whole supply chain. Thus, the profit of the whole supply chain is

$$
\pi_{c}=\left(p-c_{m}+\left(c_{s}-a\right) \varepsilon q\right)(V-b p+\gamma \lambda)-\left(\beta \lambda^{2} / 2\right)-K q^{2}
$$


Proposition 4. In the centralized decision case, the optimal decision for the whole supply chain is given as follows:

$$
\begin{gathered}
p_{c}^{*}=\frac{\left(c_{s}-a\right)^{2} V b \beta \varepsilon^{2}+2 K c_{m} \gamma^{2}-2 K b c_{m} \beta-2 K V \beta}{\left(c_{s}-a\right)^{2} b^{2} \beta \varepsilon^{2}+2 K \gamma^{2}-4 K b \beta} \\
\lambda_{c}^{*}=\frac{\left(2 K b c_{m}-2 K V\right) \gamma}{\left(c_{s}-a\right)^{2} b^{2} \beta \varepsilon^{2}+2 K \gamma^{2}-4 K b \beta} \\
q_{c}^{*}=\frac{\left(b c_{m}-V\right) b \beta\left(c_{s}-a\right) \varepsilon}{\left(c_{s}-a\right)^{2} b^{2} \beta \varepsilon^{2}+2 K \gamma^{2}-4 K b \beta}
\end{gathered}
$$

Proof of Proposition 4. To find the optimal sale price $p_{c}$, carbon emissions reduction level $\lambda_{c}$, and recovery quality level $q_{c}$, the first-order derivative of Equation 21 to $p$, $\lambda$, and $q$ can be expressed as

$$
\begin{gathered}
\frac{\partial \pi_{c}}{\partial p}=V-b p+\gamma \lambda-b\left(p-c_{m}+\left(c_{s}-a\right) \varepsilon q\right) \\
\frac{\partial \pi_{c}}{\partial \lambda}=\left(p-c_{m}+\left(c_{s}-a\right) \varepsilon q\right) \gamma-\beta \lambda \\
\frac{\partial \pi_{c}}{\partial q}=(V-b p+\gamma \lambda)\left(c_{s}-a\right) \varepsilon-2 K q
\end{gathered}
$$

The Hessian matrix of the objection functions of the whole supply chain's profit is expressed as follows:

$$
H\left(\pi_{c}\right)=\left[\begin{array}{ccc}
-2 b & \gamma & -b \varepsilon\left(c_{s}-a\right) \\
\gamma & -\beta & \left(c_{s}-a\right) \varepsilon \gamma \\
-b \varepsilon\left(c_{s}-a\right) & \left(c_{s}-a\right) \varepsilon \gamma & -2 K
\end{array}\right]
$$

According to this paper's assumptions, we derive $\left|H\left(\pi_{c}\right)_{1}\right|=-2 b<0$ and $\left|H\left(\pi_{c}\right)_{2}\right|=2 b \beta-\gamma^{2}>0$, if $\quad\left|H\left(\pi_{c}\right)_{3}\right|=\left(\gamma^{2}-2 b \beta\right) 2 K+\beta b^{2} \varepsilon^{2}\left(c_{s}-a\right)^{2}<0$, which indicates that the Hessian matrix will be negative-definite. Therefore, when $\left(\gamma^{2}-2 b \beta\right) 2 K+\beta b^{2} \varepsilon^{2}\left(c_{s}-a\right)^{2}<0, \quad$ i.e. $\quad 0<\varepsilon<\sqrt{\frac{\left(2 b \beta-\gamma^{2}\right) 2 K}{\beta b^{2}\left(c_{s}-a\right)^{2}}}, \quad$ the objection functions of the whole supply chain's revenue are jointly concave in $(p, \lambda, q)$. For that reason, we can obtain the unique optimal solutions $\left(p_{c}^{*}, \lambda_{c}^{*}, q_{c}^{*}\right)$ with the conditions assumed by the following first-order differential equations: 


$$
\left\{\begin{array}{l}
\frac{\partial \pi_{c}}{\partial p}=V-b p+\gamma \lambda-b\left(p-c_{m}+\left(c_{s}-a\right) \varepsilon q\right)=0 \\
\frac{\partial \pi_{c}}{\partial \lambda}=\left(p-c_{m}+\left(c_{s}-a\right) \varepsilon q\right) \gamma-\beta \lambda=0 \\
\frac{\partial \pi_{c}}{\partial q}=(V-b p+\gamma \lambda)\left(c_{s}-a\right) \varepsilon-2 K q=0
\end{array}\right.
$$

Solving Equation 29, Equations 22, 23, and 24 can be obtained; thus, Proposition 4 is proven.

Using Equations 22, 23 and 21, $\pi_{c}^{*}$ can be expressed as follows:

$$
\pi_{c}=\frac{-\left(b c_{m}-V\right)^{2} K \beta}{\left(\left(c_{s}-a\right)^{2} b^{2} \beta \varepsilon^{2}+2 K \gamma^{2}-4 K b \beta\right)}
$$

Proposition 5. In both centralized decision cases and decentralized decision cases, the supply chain profit, sales price, carbon emissions reduction level, and recycled product quality level satisfy the following relationships:

$$
\text { i) } \pi_{c}^{*}>\pi \text {, ii) } p_{c}^{*}<p^{*} \text {, iii) } \lambda_{c}^{*}>\lambda^{*} \text {, iv) } q_{c}^{*}>q^{*} \text {. }
$$

Proof of Proposition 5. Using Equations 20 and 30, Equations 17 and 22, Equations 10 and 23, and Equations 11 and 24, respectively, we can obtain

$$
\begin{gathered}
\Delta \pi=\pi_{c}^{*}-\pi=\frac{(-16) b^{2}\left(b c_{m}-V\right)^{2} K^{3} \beta^{3}}{\left(\left(c_{s}-a\right)^{2} b^{2} \beta \varepsilon^{2}+2 K \gamma^{2}-4 K b \beta\right)\left(\left(c_{s}-a\right)^{2} \beta b^{2} \varepsilon^{2}+2 K \gamma^{2}-8 K \beta b\right)^{2}}>0 \\
\Delta p=p_{c}^{*}-p^{*}=\frac{8 K^{2} \beta\left(V-b c_{m}\right)\left(\gamma^{2}-\beta b\right)}{\left(\left(c_{s}-a\right)^{2} b^{2} \beta \varepsilon^{2}+2 K \gamma^{2}-4 K b \beta\right)\left(\left(c_{s}-a\right)^{2} \beta b^{2} \varepsilon^{2}+2 K \gamma^{2}-8 K \beta b\right)}<0 \\
\Delta \lambda=\lambda_{c}^{*}-\lambda^{*}=\frac{-8 \beta b\left(b c_{m}-V\right) K^{2} \gamma}{\left(\left(c_{s}-a\right)^{2} b^{2} \beta \varepsilon^{2}+2 K \gamma^{2}-4 K b \beta\right)\left(\left(c_{s}-a\right)^{2} \beta b^{2} \varepsilon^{2}+2 K \gamma^{2}-8 K \beta b\right)}>0 \\
\Delta q=q_{c}^{*}-q^{*}=\frac{-4 K\left(b c_{m}-V\right)\left(c_{s}-a\right) \beta^{2} b^{2} \varepsilon}{\left(\left(c_{s}-a\right)^{2} b^{2} \beta \varepsilon^{2}+2 K \gamma^{2}-4 K b \beta\right)\left(\left(c_{s}-a\right)^{2} \beta b^{2} \varepsilon^{2}+2 K \gamma^{2}-8 K \beta b\right)}>0
\end{gathered}
$$

i.e., $\pi_{c}^{*}>\pi, p_{c}^{*}<p^{*}, \lambda_{c}^{*}>\lambda^{*}$, and $q_{c}^{*}>q^{*}$. Thus, Proposition 5 is proven.

Proposition 5 shows that, compared with a decentralized decision, a centralized decision for the supply chain yields greater profits, produces a greater reduction in 
carbon emissions, and provides consumers with lower prices, but also has higher requirements for the quality of recycled products.

\section{Results and numerical analysis}

We further verify and analyze the above conclusions through numerical examples. The definite values for the relevant parameters are as follows: $V=30, b=2, \gamma=1$; $a=2, K=10, \beta=20, c_{m}=6, \varepsilon=0.4$, and $c_{s}=4$. Plugging the above values of the relevant parameters into the models, we obtain the values of the sales price, the carbon emissions reduction rate, the recycled product quality level, the manufacturer's profit, the retailer's profit, and the supply chain's profit in the two models. The two tables below show the effect of the recovery rate intensity on the optimal values in the different model, calculated using the above parameter values.

Table 1 shows that, as the recovery rate increases, the sales price decreases and the total CLSC profit and recycled product quality level increase in the centralized CLSC model. Table 2 shows that, as the recovery rate increases, the manufacturer's wholesale price decreases, the profit of retailers and manufacturers increases, and the carbon emissions reduction level and recycled product quality level increase. Comparing Tables 1 and 2, we can see that both the carbon emissions reduction level and the recovery quality level in the centralized decision case are higher than those in the decentralized decision case. That means that a focus on a centralized decision in a closed-loop supply chain will make it easier to meet emission reduction targets and recycle used products.

Table 1. The influence of recovery rate on the centralized closed-loop supply chain (CLSC) model

\begin{tabular}{c|c|c|c|c|c|c|c|c|c}
\hline \multicolumn{10}{c}{ Recovery rate intensity } \\
\hline $\boldsymbol{\varepsilon}$ & $\mathbf{0 . 1}$ & $\mathbf{0 . 2}$ & $\mathbf{0 . 3}$ & $\mathbf{0 . 4}$ & $\mathbf{0 . 5}$ & $\mathbf{0 . 6}$ & $\mathbf{0 . 7}$ & $\mathbf{0 . 8}$ & $\mathbf{0 . 9}$ \\
\hline Total CLSC profit & 41.0959 & 41.3476 & 41.7741 & 42.3862 & 43.2000 & 44.2381 & 45.5312 & 47.1204 & 49.0612 \\
Sales price & 10.5479 & 10.5207 & 10.4745 & 10.4082 & 10.3200 & 10.2075 & 10.0675 & 9.8953 & 9.6850 \\
Carbon emissions reduction level & 0.2283 & 0.2297 & 0.2321 & 0.2355 & 0.2400 & 0.2458 & 0.2530 & 0.2678 & 0.2726 \\
Recycled product quality level & 0.0913 & 0.1838 & 0.2785 & 0.3768 & 0.4800 & 0.5898 & 0.7083 & 0.8377 & 0.9812 \\
\hline
\end{tabular}

Table 2. The influence of recovery rate on the decentralized CLSC model

\begin{tabular}{c|c|c|c|c|c|c|c|c|c}
\hline \multicolumn{10}{c}{ Recovery rate intensity } \\
\hline $\boldsymbol{E}$ & $\mathbf{0 . 1}$ & $\mathbf{0 . 2}$ & $\mathbf{0 . 3}$ & $\mathbf{0 . 4}$ & $\mathbf{0 . 5}$ & $\mathbf{0 . 6}$ & $\mathbf{0 . 7}$ & $\mathbf{0 . 8}$ & $\mathbf{0 . 9}$ \\
\hline CLSC profit & 30.6713 & 30.7955 & 31.0046 & 31.3019 & 31.6920 & 32.1813 & 32.7781 & 33.4929 & 34.3389 \\
Manufacturer's profit & 20.3979 & 20.4597 & 20.5636 & 20.7108 & 20.9032 & 21.1433 & 21.4342 & 21.7800 & 22.1857 \\
Retailer's profit & 10.2734 & 10.3358 & 10.4410 & 10.5911 & 10.7888 & 11.0380 & 11.3439 & 11.7129 & 12.1532 \\
Sales price & 12.7902 & 12.7835 & 12.7723 & 12.7563 & 12.7355 & 12.7095 & 12.6780 & 12.6405 & 12.5965 \\
Carbon emissions reduction level & 0.1133 & 0.1137 & 0.1142 & 0.1151 & 0.1161 & 0.1175 & 0.1191 & 0.1210 & 0.1233 \\
Recycled product quality level & 0.0453 & 0.0909 & 0.1371 & 0.1842 & 0.2323 & 0.2819 & 0.3334 & 0.3872 & 0.4437 \\
Wholesale price & 10.5238 & 10.5102 & 10.4874 & 10.4551 & 10.4129 & 10.3602 & 10.2964 & 10.2205 & 10.1315 \\
\hline
\end{tabular}

The unit cost savings through remanufacturing reflect the manufacturer's remanufacturing capacity, but also affect the supply chain profit and other variables. 
The influence of the unit cost savings through remanufacturing on both CLSC models is shown in Figures 1 and 2.

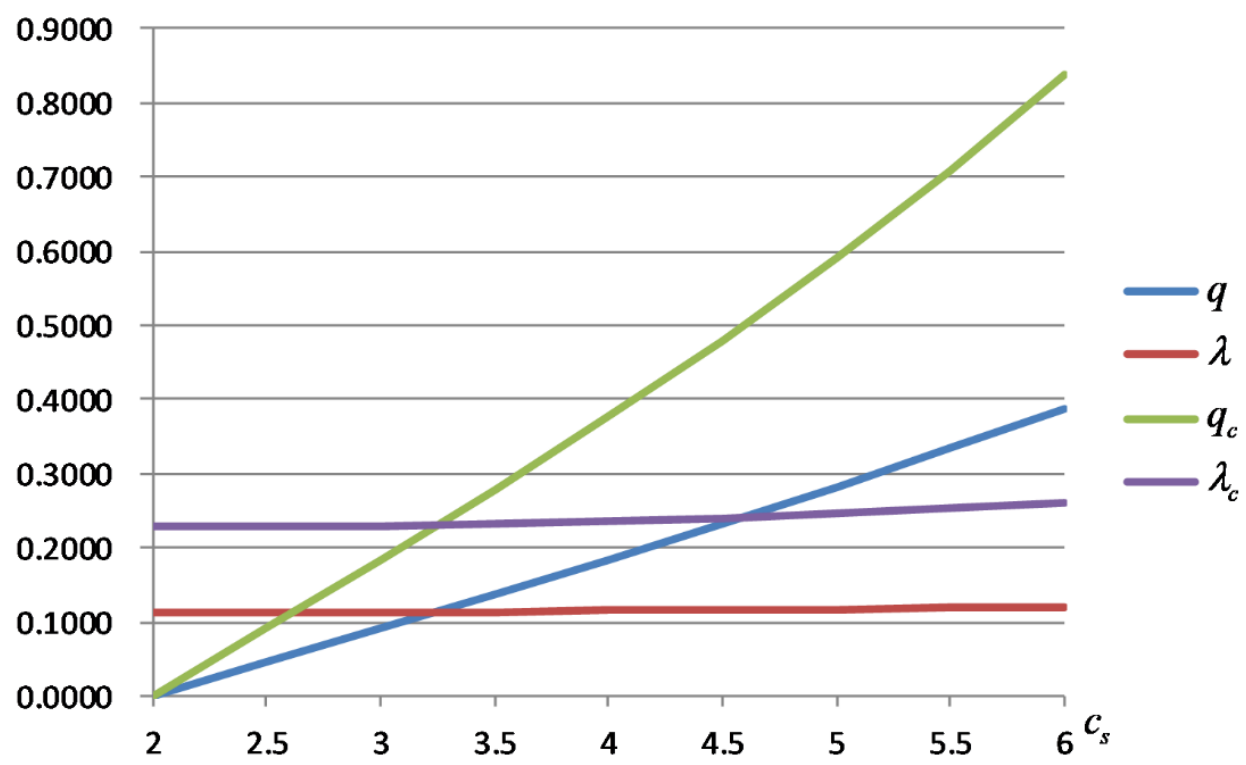

Figure 1. The effects of $C_{s}$ on the carbon emissions reduction level and the recycled product quality level

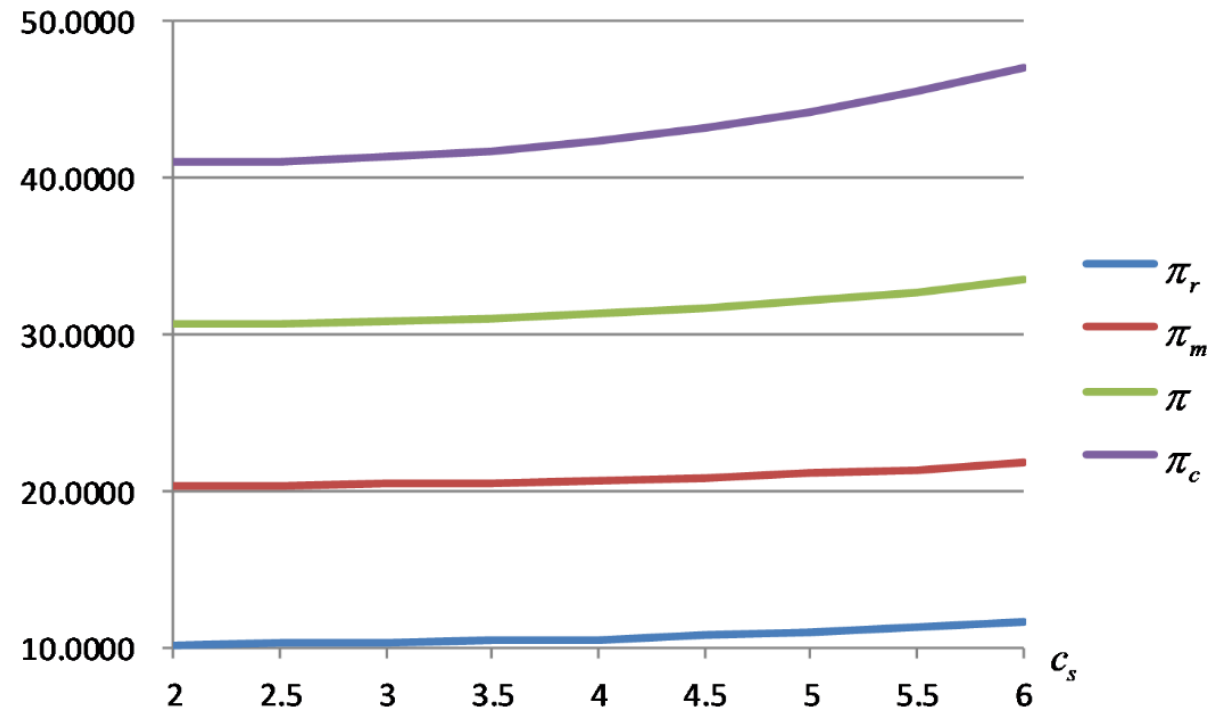

Figure 2. The effects of $C_{s}$ on profits

Figure 1 shows that, as the unit cost saving increases, the recovery quality increases, and the range of variation in the centralized decision case is greater than that in the decentralized decision case. The change in unit cost savings has less of an impact on the carbon emissions reduction level. However, the carbon emissions reduction level in the centralized decision case is still greater than that in the decentralized decision case. 
Figure 2 shows that, as the cost savings increase, the profit of the supply chain increases in the decentralized decision case and the centralized decision case, and the profit in the centralized decision case increases faster. This means that, with an increase in cost savings, manufacturers are more willing to recycle used products and earn more from recycling old products. Manufacturers recycle used products more; the lower the unit production costs, and the lower the wholesale prices, the more profit that retailers obtain.

Figure 3 shows that the recovery rate is proportional to the recycled product quality level and the carbon emissions reduction level. In the centralized decision case, the requirements for the quality level of recycled products are higher than those in the decentralized decision case. The impact of recovery rate on the carbon emissions reduction level is not significant. In comparison, the effect of recovery rate on the carbon emissions reduction level in the centralized decision case is better.

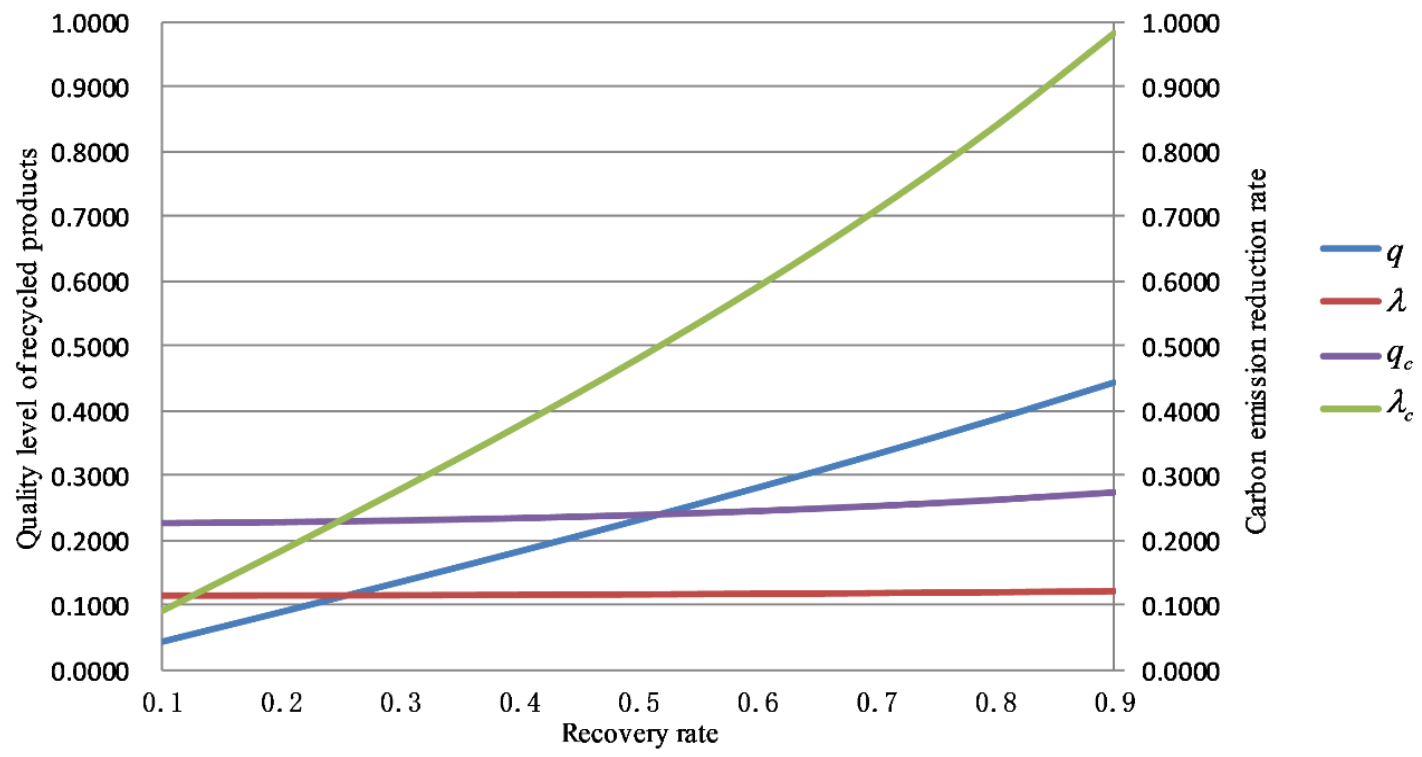

Figure 3. The effects of $\varepsilon$ on the recycled product quality level and the carbon emissions reduction level

\section{Conclusions and discussion}

In this study, we proposed CLSC decision models consisting of a manufacturer and a retailer in which manufacturers recycle used products directly and improve the quality level of the used products through their recycling efforts. We investigated how carbon emissions reduction and pricing decisions in a CLSC are affected by the quality level of recycled products, and how the market demand depends on the sales price and the carbon emissions reduction level.

This paper compared a centralized decision model with a decentralized decision model, and investigated the changes in the optimal recycled product quality level and the profit of the supply chain members, as well as the pricing and carbon emissions reduction decisions, under the two models. The effects of the recovery rate, remanufacturing cost savings, the recovery price, the carbon emissions reduction investment cost coefficient, and the recovery effort cost coefficient on the quality level of recycled products were analyzed. Our conclusions can be summarized as follows: 
An increase in the recycling rate and the unit cost savings through remanufacturing will increase the quality level of recycled products as well as the carbon emissions reduction level. However, the increase in the carbon emissions reduction level is not significant.

Compared with the decentralized decision case, the centralized decision case has higher requirements on the quality level of recycled products and is more conducive to the reduction of carbon emissions per unit product.

The sales price in the centralized decision case is lower than that in the decentralized decision case, and the recovery price also has a positive effect on sales pricing. Improving consumers' environmental awareness not only helps the sustainable closedloop supply chain members set higher prices, but also improves the quality level of recycled products.

Although we have contributed to the literature on closed-loop supply chains, our work has its limitations. First, we assumed that the manufacturer recycles used products that are recovered directly from consumers. However, in reality, used products can also be recycled by retailers or third-party recyclers. Therefore, this study could be extended in the future by considering different recycling channels. Second, we only considered investments in carbon emissions reduction for new products in this paper. Thus, future research could further consider carbon abatement investments in new and remanufactured products together. Third, we considered as identical new products and remanufactured ones. Therefore, future research could consider consumers' different preferences for new products and remanufactured products and study the impact of the quality level of recycled products on sustainable closed-loop supply chain decisions based on consumers' behavioral preferences.

Acknowledgements. The authors thank the editor and the three anonymous referees for their constructive comments and suggestions. This work was supported by the Humanities and Social Sciences Research Program of Shandong Education Department, No. J18RA088.

\section{REFERENCES}

[1] Atasu, A., Toktay, L. B., Van Wassenhove, L. N. (2013): how collection cost structure drives a manufacturer's reverse channel choice. - Production and Operations Management 22: 1089-1102.

[2] Bazan, E., Jaber, M. Y., Zanoni, S. (2017): Carbon emissions and energy effects on a two-level manufacturer-retailer closed-loop supply chain model with remanufacturing subject to different coordination mechanisms. - International Journal of Production Economics 183: 394-408.

[3] Brandenburg, M., Govindan, K., Sarkis, J., Seuring, S. (2014): Quantitative models for sustainable supply chain management: developments and directions. - European Journal of Operational Research 233: 299-312.

[4] Bulmus, S. C., Zhu, S. X., Teunter, R. H. (2014): Optimal core acquisition and pricing strategies for hybrid manufacturing and remanufacturing systems. - International Journal of Production Research 52: 6627-6641.

[5] Chen, W., Kucukyazici, B., Verter, V., Jesús Sáenz, M. (2015): Supply chain design for unlocking the value of remanufacturing under uncertainty. - European Journal of Operational Research 247: 804-819. 
[6] Ding, H., Zhao, Q., An, Z., Xu, J., Liu, Q. (2015): Pricing strategy of environmental sustainable supply chain with internalizing externalities. - International Journal of Production Economics 170: 563-575.

[7] Dobos, I., Richter, K. (2006): A production/recycling model with quality consideration. International Journal of Production Economics 104: 571-579.

[8] Fang, X., Du, Y., Qiu, Y. (2017): Reducing carbon emissions in a closed-loop production routing problem with simultaneous pickups and deliveries under carbon cap-and-trade. Sustainability-Basel 9: 2198.

[9] Fareeduddin, M., Hassan, A., Syed, M. N., Selim, S. Z. (2015): The impact of carbon policies on closed-loop supply chain network design. - Procedia CIRP 26: 335-340.

[10] Feng, W., Ji, G., Pardalos, P. M. (2017): Effects of government regulations on Manufacturer's behaviors under carbon emission reduction. - Environmental Science and Pollution Research. https://doi.org/10.1007/s11356-017-0891-4.

[11] Ferrer, G., Swaminathan, J. M. (2006): Managing new and remanufactured products. Management Science 52: 15-26.

[12] Galbreth, M. R., Blackburn, J. D. (2006): Optimal acquisition and sorting policies for remanufacturing. - Production and Operations Management 15: 384-392.

[13] Gan, S., Pujawan, I. N., Suparno, W, B. (2017): Pricing decision for new and remanufactured product in a closed-loop supply chain with separate sales-channel. International Journal of Production Economics 190: 120-132.

[14] Gao, J., Han, H., Hou, L., Wang, H. (2016): Pricing and effort decisions in a closed-loop supply chain under different channel power structures. - Journal of Cleaner Production 112: 2043-2057.

[15] Ghosh, D., Shah, J. (2012): A comparative analysis of greening policies across supply chain structures. - International Journal of Production Economics 135: 568-583.

[16] Govindan, K., Soleimani, H., Kannan, D. (2015): Reverse logistics and closed-loop supply chain: a comprehensive review to explore the future. - European Journal of Operational Research 240: 603-626.

[17] Govindan, K., Madan, S. K., Kannan, D. (2016): Application of fuzzy analytic network process for barrier evaluation in automotive parts remanufacturing towards cleaner production - a study in an Indian scenario. - Journal of Cleaner Production 114: 199-213.

[18] Guide, V. D. R. J., Teunter, R. H., Van Wassenhove, L. N. (2003): Matching demand and supply to maximize profits from remanufacturing. - Manufacturing \& Service Operations Management 5: 303-316.

[19] He, R., Xiong, Y., Lin, Z. (2016): Carbon emissions in a dual channel closed loop supply chain: the impact of consumer free riding behavior. - Journal of Cleaner Production 134: 384-394.

[20] Jerbia, R., Kchaou Boujelben, M., Sehli, M. A., Jemai, Z. (2018): A stochastic closedloop supply chain network design problem with multiple recovery options. - Computers \& Industrial Engineering 118: 23-32.

[21] Ke, H., Wu, Y., Huang, H., Chen, Z. (2018): Optimal pricing decisions for a closed-loop supply chain with retail competition under fuzziness. - Journal of the Operational Research Society 69: 1468-1482.

[22] Li, H., Wang, C., Shang, M., Ou, W. (2017): Pricing, carbon emission reduction, lowcarbon promotion and returning decision in a closed-loop supply chain under vertical and horizontal cooperation. - International Journal of Environmental Research and Public Health 14: 1332.

[23] Liu, Z. L., Anderson, T. D., Cruz, J. M. (2012): Consumer environmental awareness and competition in two-stage supply chains. - European Journal of Operational Research 218: 602-613.

[24] Metta, H., Badurdeen, F. (2013): Integrating sustainable product and supply chain design: modeling issues and challenges. - IEEE Transactions on Engineering Management 60: 438-446. 
[25] Mukhopadhyay, S. K., Ma, H. (2009): Joint procurement and production decisions in remanufacturing under quality and demand uncertainty. - International Journal of Production Economics 120: 5-17.

[26] Olugu, E. U., Wong, K. Y. (2012): An expert fuzzy rule-based system for closed-loop supply chain performance assessment in the automotive industry. - Expert Systems with Applications 39: 375-384.

[27] Özkır, V., Başlıgıl, H. (2012): Modelling product-recovery processes in closed-loop supply-chain network design. - International Journal of Production Research 50: 22182233.

[28] Rahman, S., Subramanian, N. (2012): Factors for implementing end-of-life computer recycling operations in reverse supply chains. - International Journal of Production Economics 140: 239-248.

[29] Savaskan, R. C., Van Wassenhove, L. N. (2006): Reverse channel design: the case of competing retailers. - Management Science 52: 1-14.

[30] Savaskan, R. C., Bhattacharya, S., Van Wassenhove, L. N. (2004): Closed-loop supply chain models with product remanufacturing. - Management Science 50: 239-252.

[31] Shu, T., Liu, Q., Chen, S., Wang, S., Lai, K. (2018): Pricing decisions of CSR closedloop supply chains with carbon emission constraints. - Sustainability-Basel 10: 4430.

[32] Swaminathan, J. M., Ferrer, G. (2010): Managing new and differentiated remanufactured products. - European Journal of Operational Research 203: 370-379.

[33] Taleizadeh, A. A., Moshtagh, M. S., Moon, I. (2017): Optimal decisions of price, quality, effort level and return policy in a three-level closed-loop supply chain based on different game theory approaches. - European Journal of Industrial Engineering 11: 486-525.

[34] Taleizadeh, A. A., Moshtagh, M. S., Moon, I. (2018): Pricing, product quality, and collection optimization in a decentralized closed-loop supply chain with different channel structures: Game theoretical approach. - Journal of Cleaner Production 189: 406-431.

[35] Tan, Y., Guo, C. (2019): Research on two-way logistics operation with uncertain recycling quality in government multi-policy environment. - Sustainability-Basel 11: 882.

[36] Tao, Z. G., Guang, Z. Y., Hao, S., Song, H. J., Xin, D. G. (2015): Multi-period closedloop supply chain network equilibrium with carbon emission constraints. - Resources, Conservation and Recycling 104: 354-365.

[37] Turki, S., Rezg, N. (2018): Impact of the quality of returned-used products on the optimal design of a manufacturing/remanufacturing system under carbon emissions constraints. Sustainability-Basel 10: 3197.

[38] Xu, L., Wang, C. (2018): Sustainable manufacturing in a closed-loop supply chain considering emission reduction and remanufacturing. - Resources, Conservation and Recycling 131: 297-304.

[39] Xu, Z., Pokharel, S., Elomri, A., Mutlu, F. (2017): Emission policies and their analysis for the design of hybrid and dedicated closed-loop supply chains. - Journal of Cleaner Production 142: 4152-4168.

[40] Yang, L., Zhang, Q., Ji, J. (2017): Pricing and carbon emission reduction decisions in supply chains with vertical and horizontal cooperation. - International Journal of Production Economics 191: 286-297.

[41] Zhang, J. Kevin Chiang, W. Y., Liang, L. (2014): Strategic pricing with reference effects in a competitive supply chain. - Omega 44: 126-135.

[42] Zou, Q., Ye, G. (2015): Pricing-decision and coordination contract considering product design and quality of recovery product in a closed-loop supply chain. - Mathematical Problems in Engineering 593123: 1-14. 